\title{
Intentional Learning as a Principle for ESL Writing Instruction: A Case Study *
}

\author{
Alister Cumming
}

This paper first discusses the principle of intentional learning then reports on a case study investigating the application of this principle to instruction in ESL writing. Twenty, young adult ESL students of engineering were asked to select goals for their writing development, to monitor their attempts to achieve these goals during writing tasks, and to assess their learning achievements. Data collected from students' reports, think-aloud pro- tocols, and analyses of achievement in composition writing indicate that most learners were able to use this form of learning to make discernable achievements in their writing proficiency. The instructional design used to promote intentional learning in the ESL writing course is described. Implications for ESL instruction and theories of learning are discussed.

Writing is an activity which allows for distinctions between relatively unconscious, automatic behaviour and conscious deliberations or reflections. The processes of reflection offer a potential for those intending to improve their writing to think about their performance as they write and to alter their behaviour in such ways as to direct their procedures for performing toward meeting their aims for improvement. If learners are able to make use of this potential to direct themselves, as they write, toward successive improvements in their overall abilities to write, this capacity offers a profound principle of learning on which to base instructional design for second language composition courses.

Research in cognitive psychology ${ }^{1}$ has recently made much of this principle. Flavell (1979, p. 908) suggests that cognitive processes are capable of being controlled by a more general process of "metacognition" which is "especially likely to occur in situations that stimulate a lot of careful, highly conscious thinking". Anderson (1982) distinguishes between procedural knowledge (abilities to perform) and declarative knowledge (propositions about performance abilities), mak-

* I thank several people for their helpful, encouraging comments at various points in the preparation of this paper or during this research: Dick Allwright, Carl Bereiter, Andrew Cohen, Ron Mackay, Francis Mangubhai, David Mendelsohn, Razika Sanaoui and Merrill Swain. The research discussed in the paper is described more fully in Cumming (1985b). 
ing claims for necessary interactions between the two in the cognitive processes of learning. Sternberg (1984) defines seven components of human intelligence which may have 'executive' functions, exerting control over a person's thought and behaviour when they are necessary. Bereiter \& Scardamalia (1982, p. 5) present a rationale for application of these principles to education, claiming that learning experiences where "the mind gains control over its own working" are more valuable than those where individuals merely learn by participating in certain situations. Their conception of "intentional cognition" suggests that learning is most effective when learners come to impose their intentions on a context rather than merely responding to the demands which a context creates. These principles are especially relevant to the learning of composition (Scardamalia \& Bereiter, 1985), where people engage in a kind of problem-solving that requires great mental effort to create written objects which are able, effectively, to define their own substantive contexts.

Related thinking has appeared in some studies of second language learning. There has been speculation on the psychological procedures which learners may employ to match their behaviour to characteristics they consider salient in their environment (McLaughlin, 1978, pp. 320324; Widdowson, 1983a, pp. 88-89). Kasper (1984, p. 18), in adopting Anderson's (1982) definition of learning, concludes that second language students should be encouraged to "achieve some cognitive control over their procedural knowledge". Research on course design for adult students has stressed the importance of learners arranging their personal conditions for language study autonomously (Holec, 1985) and of instruction which encourages learners to organize the development of their strategies for performing in a second language (Carver, 1984).

Research on composing in a second language has approached similar ground. In examining the performance of students learning to write in their second language, there has been a concentration of attention on the cognitive processes which learners use as they write. Indeed, this research is fast approaching the inevitable conclusion that learning to write in a second language is something that people learn to do as they write. There have been substantial refutations of the once-popular notions that the development of writing proficiency in a second language might be determined by: linguistic-cultural patterns of rhetoric (Mohan \& Lo, 1985), students' processing of their teachers' feedback on their compositions (Cohen, in press; Cumming, 1985a; Zamel, 1985), or teachers possessing the totalitarian powers to lead learners from "controlled composition" to "free expression". Instead, it is evident in the details of studies such as those of Jones (1983), Raimes (1985), and Zamel (1983) that the psychological procedures which ESL students use as they write are integral to the writing they produce, are 
of great complexity, tend to vary among individuals, and develop with improved proficiency.

However, there have been few principled attempts to explain learning to write in a second language. Krashen (1984) has outlined what may be the minimal conditions-reading and practice writing. Widdowson (1983b) finds the basis for a developmental sequence in learners' mastery of textual features of a second language. He proposes that as learners gradually gain control over the textual features of their second language, this facilitates their being able to devote their attention to expression, communication and social expectations. Zamel (1982) considers learning to occur through ESL students concentrating on the meanings they discover and produce while composing. If learners are able to refine their thoughts and expressions meaningfully in preparing and revising drafts of their compositions, they are thereby able to develop their writing proficiency.

Yet each of these explanations presumes that learning to write in a second language occurs merely through students' participation in writing activity. There are few suggestions that those learning to write in a second language might be able to take responsibility for their learning, either psychologically or in respect to course design or instruction. The image of the second language student learning to write which is portrayed in the current professional literature (and which is undoubtedly enacted in many classrooms) is that of a determined but frustrated individual, struggling to complete yet another draft of the same, tiresome composition in hopes of accomplishing improved writing proficiency in an inexplicable way. The written product might improve with each draft, but what has been learned? If learning does occur in the act of writing, what procedures might learners follow to direct this process? Most importantly, how might learners be able do direct their own cognitive procedures as they write?

\section{A CASE STUDY}

Principles of intentional cognition and certain studies in mothertongue writing instruction suggest ways in which learning itself might become a featured emphasis of education rather than a mystery eluding both student and teacher. In order to investigate the application of these principles, as well as their relevance to ESL writing instruction, a case study was undertaken in a composition course for ESL students taught by the author in the Faculty of Engineering at the University of Toronto in the autumn of 1984 . The details of the study, described more fully in Cumming (1985b); were encouraging and show promise for a principled development of instructional design based on intentional learning 
theory in adult ESL composition courses. The research described below was conducted in an exploratory way, as a case study rather than experimental study. Its results are tentative and in need of further substantiation. The roles of instructor and researcher were combined in the study and there was no control group, but the procedures and results of this investigation are related to many concerns in curriculum studies as well as applications of learning theory.

The purpose of the study was to investigate:

1. the validity of an instructional design based on principles of intentional learning;

2. the abilities of adult ESL learners:

- to select appropriate goals for their learning in this context,

- to act on these goals while they performed writing tasks,

- to monitor their achievement of these goals over consecutive tasks,

- to develop their capacities to select, act on, and monitor their goal selection, writing performance, and achievement;

3. the effectiveness of the learning outcomes in terms of conventional assessments of writing proficiency.

The twenty students in the course came from diverse cultural backgrounds (75\% from various Asian countries, $20 \%$ from European countries, 5\% from Quebec) and were in their first or second years of academic programs in engineering.

\section{Instructional Design}

An instructional framework in five phases was designed for the course (see Figure 1). Each stage was devised to correspond to hypothetically ${ }^{2}$ sufficient conditions for intentional learning. Each phase lasted about one week. The design was implemented twice during the twelve weeks of the course.

The students were first asked to choose appropriate goals for their learning. This was done in a context where students could compare their writing procedures and products with those of the instructor-allowing the students as "novices" to examine their writing in relation to that of a more proficient performer in this activity. To initiate this, the instructor first modelled his thinking aloud as he wrote a composition (i.e. saying aloud everything he was thinking about as he wrote) in front of the class. Students were asked to take notes on the procedures the instructor used while writing. They were then told to write on a similar task, modelling their thinking aloud in small groups of their peers, and to write up notes on the procedures they used themselves while writing. Their compositions were next collected and reformulated (following 


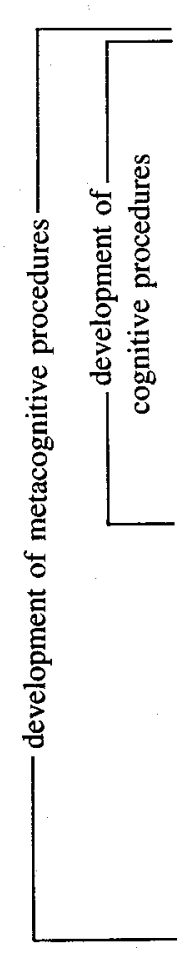

1. setting learning goals within a context and task

- task performance by learners and instructor

- comparison of novice/expert performances

- analysis of performances and texts

- setting goals individually

2. realizing learning goals in a context and task

- statement of appropriate goals for learning

- task performance in view of learning goals

- comparison of peer performances

3. acknowledging that learning goals have been realized

- analysis of own performance

- reanalysis of learning goals and their realizations

- instructional feedback in view of goals and texts

4. transfer of learning goals to similar contexts and tasks

- reanalysis of learning goals

- statement of goals for performance

- repeated task performances (i.e. practice) and analyses

5. acknowledging that learning goals have been set, realized, acknowledged and transferred

- comparison of own task performances and texts

- self-assessment of learning goals, performances, and instructional feedback

- development of metacognitive abilities to produce, monitor and adjust: goal selection, realization, acknowledgement, and transfer

Figure 1. Phases in an instructional design for intentional learning in adult ESL writing development.

Cohen, 1983) by the instructor, who rewrote each composition to retain most of the original content but to improve on the syntax, lexis and style. On the basis of analyzing their notes and reformulated text-comparing how and what each student wrote with how and what the instructor wrote-students were asked to select at least one goal toward which they each intended to improve their writing abilities over the following five weeks. The students did not appear to have difficulties selecting goals for themselves.

In the second phase of the instructional design, students were asked to perform a writing task with the intention of realizing their individual goals for learning. After completing the task, they were instructed to write out an analysis of their attempts to achieve their goals, to explain why or why not they might have achieved the goals, and to assess the appropriateness of the goal(s) they had chosen. These self-analyses were shared in discussions among groups of the students.

The self-analyses of achievements and difficulties, along with feedback from the instructor on the completed compositions in view'of each 
student's goal(s), made up the third phase of the instructional design. The fourth phase repeated the activities of the second and third phases, except that students were asked to continue to pursue the same goals in several more writing tasks. In the fifth phase, students reviewed all their earlier performances, assessed whether or not they had, over several weeks, been able to achieve their goals, and wrote out statements to this effect for the instructor. In theory, the earlier phases encouraged the development of cognitive abilities related to the goals that learners selected, whereas this final phase was meant to ensure that learners developed a metacognitive awareness of their own learning procedures.

Writing tasks involved "report-writing" in the first half of the course and "personal essays" in the second half. Report-writing tasks consisted of a) reports of interviews of other students and on group or class discussions as well as b) descriptions of scientific diagrams, objects and charts which students brought into the writing class from their other courses. Personal essays called for expositions on topics of general relevance to university students or engineers. The topics of the reports were defined by students, whereas topics for personal essays were selected by students from among a range of possible topics set out by the teacher. The students wrote one or two compositions per week, consisting of about 300 to 500 words or two to five hours of writing. Most compositions were written in two or three drafts, usually with peer commentaries on the second and third drafts.

Few instructional techniques were employed, since one aim of the course design was to have students develop their individual strategies for learning, self-monitoring, and achievement. This could hardly have been expected to occur if instructional directives dominated the learner's activities (Brannon \& Knoblauch, 1982; Clay, 1983). Some aids, such as procedural cues and suggestions for planning, revising or proofreading, were provided by the instructor. Students met often in pairs to describe their plans, to analyze, or to read aloud drafts of their compositions. On several occasions, they modelled their thinking aloud in small groups while they wrote; later, the students analyzed what their peers had said and done while they wrote. Readings about the writing processes of professional writers-such as Selzer's (1982) case study of the writing habits of an engineer-were also assigned and discussed in view of their approaches to composition.

\section{Findings}

Data were collected in reference to the kinds of learning goals which students chose, students' awareness of their having achieved their goals for learning, the alterations which students made to their learning goals during the second implementation of the instructional design, and the 
correspondence of the students' selected goals to conventional measures of their achievement in the course.

The goals which students chose in the first and second implementations of the instructional design varied considerably among the learners (see Cumming, $1985 \mathrm{~b}$ for a listing of the individual goals). Table 1 shows: 1) a categorization of the aspects of writing in which students thought they had achieved their goals for learning in the first implementation of the instructional design and 2) the goals which they selected to focus on in the second implementation of the design.

Table 1

Students' Statements of Achievements and Goals at Mid-Term*

\begin{tabular}{|c|c|c|}
\hline Aspect of Writing & $\begin{array}{l}\text { Areas of Perceived } \\
\text { Achievement over } \\
\text { First Half of Course } \\
\end{array}$ & $\begin{array}{l}\text { Learning Goals } \\
\text { Set for Second } \\
\text { Half of Course } \\
\end{array}$ \\
\hline $\begin{array}{l}\text { Budgeting time: } \\
\text { Preliminary planning }\end{array}$ & $11 \%$ & $10 \%$ \\
\hline - generating appropriate content: & $63 \%$ & $48 \%$ \\
\hline $\begin{array}{l}\text { - organizing content: } \\
\text { - putting content into rhetorical }\end{array}$ & $32 \%$ & $29 \%$ \\
\hline $\begin{array}{l}\text { form: } \\
\text { Improving texts }\end{array}$ & $58 \%$ & $33 \%$ \\
\hline - rhetorical presentation of content: & $32 \%$ & $43 \%$ \\
\hline - sentence grammar: & $16 \%$ & $33 \%$ \\
\hline - word choice: & $11 \%$ & $10 \%$ \\
\hline - punctuation and spelling: & $5 \%$ & $4 \%$ \\
\hline - avoiding unnecessary repetitions: & $11 \%$ & $10 \%$ \\
\hline Proofreading: & $32 \%$ & $10 \%$ \\
\hline
\end{tabular}

* Percentages are calculated from the total number of goals set by all students in the class, e.g. $10 \%$ of the students selected learning goals related to "budgeting their time".

Students tended to continue to pursue areas of learning where they thought they had earlier made discernable achievements. Most students chose to concentrate on goals relating to their preliminary planning for compositions, their procedures for presenting content rhetorically, or their approaches to proofreading. Attention to these areas may have come about either from the emphasis on such procedures which occurred while the instructor or other students were modelling their thinking aloud or from the learners' perceived weaknesses in these areas.

In the first implementation of the instructional design, $60 \%$ of the students estimated they had achieved their learning goals successfully, 
$25 \%$ said they had not, and $15 \%$ said they were not sure whether they had or had not. In the second implementation, $95 \%$ of the students estimated they had achieved all or some of their goals, and only one person thought he had not. These figures indicate that many students either became more adept at achieving the goals they set for themselves as the period of their study continued or became more confident in their awareness of their achievements.

The students also increased the number of goals they chose. In their first attempt, students tended to select only one learning goal (mean $=1.35$, standard deviation $=.49$, maximum $\mathrm{n}=2$ ). In the second implementation of the instructional design, they generally chose two or three goals (mean $=2.40$, standard deviation $=1.35$, maximum $\mathrm{n}=5$ ). In the second half of the course, about one third of the students retained the same goals they had set in the first half of the course, one third retained their original goals but added others onto these, and one third chose entirely new goals. However, simply increasing the number of these goals did not appear to mean that the students who set large numbers of goals for themselves thought they were able to achieve them. In fact, most of those with four or five goals thought they were only able to achieve two or three of these goals over the period of six weeks.

Aside from learners' self-assessments of their achievements, it is difficult to substantiate the level of actual attainment which may have occurred in these circumstances (cf. Oskarsson, 1978). In the context of this course, the ultimate measures of learning were students' scores on their final exams, an essay writing task on which all compositions were rated (by two ESL teachers) with a slightly modified version of Jacobs et al.'s (1981) ESL Composition profile. Since this instrument requires that ratings of compositions be done separately for four aspects of written texts (content, organization, vocabulary, and language use), this offered an opportunity to determine some areas where the students' texts demonstrated improvements in their writing. Gains in these scores were calculated (see Appendix) by subtracting students' scores on their pre-test compositions (written prior to the students' being admitted to the course) ${ }^{3}$ from their scores on their post-test compositions. The mean gain for the total group (14.6\%) is slightly higher than might usually be expected in an ESL composition for freshman students; Jacobs et al. (1981, p. 75), for instance, report a $10.5 \%$ gain using similar measures for a group of adult students in a more conventional ESL composition course.

Comparing the gain in scores shown in the Appendix with the learning goals set by individual students, there appears to be a correspondence, for most but not all learners, between their perceived areas of achievement and the analytic scorings of students' texts by two ESL 
teachers. The stated learning goals of about $65 \%$ of the students can be matched directly to the areas of improvement evident in the gain scores. This is most obvious in the cases of those students who made gains which were well above the mean gain in the subcomponents of the composition rating scales. That is, where students showed exceptionally high levels of improvement in scores of content, organization, vocabulary or language use, these improvements were made by students who chose learning goals related to these areas of their writing. Of course, the criteria used by ESL teachers in applying this rating scale need not correspond directly to the conceptions of individual ESL learners about their achievements or their writing abilities. Nevertheless, there are instances of students like $m, n$, and $q$, who set learning goals related to the "organization" of their compositions, making extraordinary gains of $24 \%$ to $28 \%$ in the ratings given to this feature of their compositions. Likewise, student $o$, who intended to learn to improve his abilities at "collecting ideas", made $35 \%$ gains in the "content" rating of his compositions. Students $h, i$, and $r$ appear to have made $25 \%$ gains in their "content" ratings by concentrating on their strategies for preliminary planning and the specification of details. Where students did not make such striking gains, their self-assessments mostly indicated they thought they had not yet achieved all their learning goals.

One instructional technique-having students model their writing processes by "thinking aloud" in front of small groups of their peers (Scardamalia \& Bereiter, 1983)-appears to have contributed to many students' development of their procedures for writing. These activities were followed by self-analyses and peer-analyses of the procedures the students had demonstrated. In one case, student $m$, who in the first implementation of the instructional design was unable to achieve his learning intention of "staying on the topic", demonstrated in a thinkaloud protocol that although he made extensive planning notes before composing, he never once referred back to these notes for guide himself when writing. This "flaw" in his procedural strategies was not at all apparent to the student himself, who continued writing (for a good halfhour) by persistently attempting to create the meaning for new sentences through rereading previous sentences he had written (rather than consulting his notes, where obvious suggestions to continue his flow of ideas lay). His peers identified this strategic problem, explaining to him that it was probably the cause of his inability to stay "on-topic" when writing. By the end of the course, the student demonstrated $24 \%$ gains in the rating given to "organization" in his compositions, and he acknowledged he had achieved his intended goals for learning.

A similar case is that of student $t$, who had initially set a learning goal of "proofreading carefully" for himself but after several tasks thought he had been unable to achieve this goal. During a think-aloud 
session he showed, as he reread and attempted to proofread one of his papers, that his conceptions of proofreading related only to the application of certain grammatical rules to his text. Thus, while proofreading, he attended to errors he knew he was prone to make-for example, with plural ' $s$ ' markers and subject-verb agreements-but he neglected entirely the sense of his writing. This procedural "flaw" was pointed out by his peers as he happily read aloud several of his sentences where his projected meaning was utterly unclear. Apparently through the student's concentrating on developing this procedure and other aspects of his procedures for producing compositions, he was able to attain an increase of $24 \%$ in the category of "language use".

\section{IMPLICATIONS}

The findings from this study have several implications of potential value for second language writing instruction. It appears that relatively proficient, motivated adult learners of ESL are able to select goals for the improvement of their writing which they consider accessible, attainable or appropriate for themselves. They seem able to practice acting on the goals they have chosen as well as to monitor their achievement of these goals with relative accuracy. As their period of study extends, these students appear able to elaborate a greater number of learning goals for their writing improvement with greater confidence in their abilities to assess their achievement. Moreover, those students in this study who seemed to have made the most achievement in particular areas of second language writing appear to have done so in relation to the goals they chose to set for themselves. Also, the students' satisfactions and the achievements they obtained appear to have demonstrated the validity of the instructional design arranged for this course in addition to the utility of modelling thinking aloud in ESL composition courses. Further investigations, however, are required to verify these points. Studies of the cognitive as well as social factors related to intentional learning need to be done in different contexts and among different groups of second language learners in order to establish more clearly its relevance to theories of learning in second language writing instruction.

This study raises several issues of concern for second language instruction. The variation in learning goals which the students selected shows the significance of individual differences among ESL learners. The study demonstrates also that adult learners can, under appropriate conditions, decide for themselves which aspects of language learning are uniquely appropriate for them. Further, as Clay (1983) notes with regard to mother-tongue composition instruction, writing development appears to be better encouraged by helping students initiate their own 
goals for learning rather than by forcing them to respond to instructional directives. In addition, this study demonstrates the importance of conceiving that language learning occurs over relatively long durations rather than in the accomplishment of one or two tasks. Many of the students in this study attended to only two or three goals over the period of twelve weeks. Their long-term achievements were rarely evident in a period of days or weeks. A related point concerns the importance of long-term monitoring of learning intentions. Though it seems that cognitive monitoring may be an undesirable activity in the performance of some activities in a second language, especially conversation at beginning levels of proficiency, it may be an extremely effective means for learners to direct their learning processes in such activities as writing, which not only allow for but require deliberate, complex thought.

\section{OTHER CONSIDERATIONS AND AREAS FOR FUTURE RESEARCH}

Certain reservations about intentional learning in second language instruction might need to be made, however. The effectiveness of this form of learning might depend on: the knowledge which learners possess, their levels of self-awareness, their performance abilities, the types of tasks required of them, and contextual constraints. It is clear that children may have few of the abilities to reflect on their activities in the ways that adults do. Indeed, Scardamalia, Bereiter and Steinbach (1984) come to the conclusion that children's abilities for reflective thought while composing may develop with cognitive maturity and thus have restrictions in language instruction for very young learners. In respect to adults, Jones (1985) observes that one ESL student's excessive monitoring of minor details in her writing distracted her from more important aspects of her composing performance. It is also possible that learners may have to acquire a requisite level of writing proficiency in a second language before they can confidently reflect on their performance while writing in such a manner as to make their reflections productive. As Cummins (1984) explains, the ability to perform complex acts of cognition in a second language may take a substantially longer time to develop than do abilities to communicate in conversation in the language. Motivation for learners to improve their writing abilities in a second language may also be a requirement for this form of learning to be effective.

Several areas might be considered for future research. Do the strategies for learning acquired in the context of a second language writing class transfer to other contexts-for writing, other aspects of second language performance, or other cognitively-demanding activities? If they 
do, then intentional learning has much to offer language students in their learning. What happens to learners who work at goal-setting procedures over a longer time than was investigated in this study? It may be that the effects of this learning, as well as learners' capacities to make use of it, could continue, diminish, or increase. What is the potential for intentional learning for students improving their ability to read in a second language? Reading, like writing, readily allows for a separation of performance and reflection, offering a similar potential for learners to direct their cognitive monitoring toward long-term goals. Do the goals which learners choose to set for themselves vary at different levels of second language proficiency? It may be that the cognitive strategies of beginning, intermediate, or advanced learners vary with their abilities to process a second language. A final question worthy of investigation is how this form of "conscious" learning relates to other forms of learning which occur in a non-analytic way, such as so-called "natural language acquisition" (see, e.g., Krashen \& Terrell, 1983). Is any one way of learning more effective, efficient, or appropriate in particular circumstances? How might different forms of learning interact psychologically, be prompted by different instructional approaches, or satisfy the aims of certain groups of learners?

\section{NOTES}

1. This research on cognition relates closely to developments in analytic philosophy. The study of intentionality has become a major concern in contemporary philosophy, starting with Anscombe's (1957) interpretations of problems posed by Wittgenstein, appearing in arguments against Skinnerian behaviourism, and culminating in mentalistic conceptions of human cognition (Dennett, 1978; Searle, 1983). Philosophers such as Bennett (1976) have suggested that human intentions determine our "capacity to learn from something" (1976, p. 119).

2. These conditions were presumed to be that learners would: 1) have opportunities to compare their writing performance and texts with those of a more proficient writer in English as a basis for selecting appropriate goals for their writing development; 2) select and state their goals autonomously; 3) engage in a sufficient number of writing tasks to allow them to act on and realize the goals they had selected; 4) monitor their achievement of the goals; and 5) participate in a supportive environment where others were performing similar activities.

3. The pre-test compositions were rated by the same two ESL teachers who assessed the post-test compositions. These raters assessed both sets of compositions at the same time, without being told which compositions were pre-tests or post-tests.

\section{REFERENCES}

Anderson, J.R. (1982). Acquisition of cognitive skill. Psychological Review, $89(2), 369-406$.

Anscombe, G.E.M. (1957). Intention. Ithaca, N.Y.: Cornell University Press.

Bennett, J. (1976). Linguistic Behaviour. Cambridge: Cambridge University Press. 
Bereiter, C. \& Scardamalia, M. (1982). Schooling and the growth of intentional cognition. In Z. Lamm (Ed.), New trends in education. Tel-Aviv: Yachdev.

Brannon, L. \& Knoblauch, C. (1982). On students' rights to their own texts: a model of teacher response. College Composition and Communication, 33(2), 157-166.

Carver, D. (1984). Plans, learner strategies and self-direction in language learning. System, 12(2), 123-131.

Clay, M. (1983). Getting a theory of writing. In B. Kroll \& G. Wells (Eds.), Explorations in the development of writing. New York: John Wiley.

Cohen, A. (1983). Reformulating compositions. TESOL Newsletter, 17(6), 1, 4-5.

Cohen, A. (in press). Student processing of feedback in their compositions. In A. Wenden \& J. Rubin (Eds.), Learner strategies: implications for second language teacher and researcher. Oxford: Pergamon.

Cumming, A.H. (1985a). Responding to the writing of ESL students. In M. Maguire \& A. Pare (Eds.), Patterns of development. Ottawa: Canadian Council of Teachers of English.

Cumming, A.H. (1985b). Intentional strategies in writing development in LSP. In L.K. Engels (Ed.), Proceedings of the 5th European Symposium on Languages for Specific Purposes. Leuven, Belgium: Institut voor Levende Talen.

Cummins, J. (1984). Bilingualism and special education: issues in assessment and pedagogy. Clevedon, Avon: Multilingual Matters.

Dennett, D. (1978). Brainstorms. Harvard, Mass.: MIT Press.

Flavell, J.H. (1979). Metacognition and cognitive monitoring. American Psychologist 34(10), 906-911.

Holec, H. (1985). On autonomy; some elementary concepts. In P. Riley (Ed.), Discourse and learning. London: Longman.

Jones, C.S. (1983). Attention to thetorical information while composing in a second language. In C. Campbell, V. Flashner, T. Hudson \& J. Lubin (Eds.), Proceedings of the Los Angeles second language research forum, vol. 2. Los Angeles: UCLA.

Jones, C.S. (1985). Problems with monitor use in second language composing. In M. Rose (Ed.), When a writer can't write. New York: Guilford.

Kasper, G. (1984). Pragmatic comprehension in learner-native speaker discourse. Language Learning, 34(4), 1-20.

Krashen, S.D. (1984). Writing: research, theory, and applications. Oxford: Pergamon.

Krashen, S.D. \& Terrell, T. (1983). The natural approach. Oxford: Pergamon.

McLaughlin, B. (1978). The monitor model: some methodological considerations. Language Learning, 28(2), 309-322.

Mohan, B. \& Lo, W.A. (1985). Academic writing and Chinese students: transfer and developmental factors. TESOL Quarterly, 19(3), 515-534.

Oskarsson, M. (1978). Approaches to self-assessment in foreign language learning. Oxford: Pergamon.

Raimes, A. (1985). What unskilled ESL writers do as they write. TESOL Quarterly, 19(2), 229-258.

Scardamalia, M. \& Bereiter, C. (1983). Child as co-investigator: helping chil- 
dren gain insight into their own cognitive processes. In S. Paris (Ed.), Learning and motivation in the classroom. Hillsdale, N.J.: Erlbaum.

Scardamalia, M. \& Bereiter, C. (1985). Dialectical processes in composition. In D.R. Olson, N. Torrance \& A. Hildyard (Eds.), Language, literacy and learning. Cambridge: Cambridge University Press.

Scardamalia, M., Bereiter, C. \& Steinbach, R. (1984). Teachability of reflective processes in written composition. Cognitive Science, 8(2), 173-190.

Searle, J.R. (1983). Intentionality. Cambridge: Cambridge University Press.

Selzer, J. (1983). The composing processes of an engineer. College Composition and Communication, 34(2), 178-187.

Sternberg, R.J. (1984). Toward a triarchic theory of human intelligence. Behavioral and Brain Sciences, 7(2), 269-315.

Widdowson, H.G. (1983a). Learning purpose and language use. Oxford: Oxford University Press.

Widdowson, H.G. (1983b). New starts and different kinds of failure. In A. Freedman, I. Pringle \& J. Yalden (Eds.), Learning to write: first language/ second language. London: Longman.

Zamel, V. (1982). Writing: the process of discovering meaning. TESOL Quarterly, 16(2), 195-209.

Zamel, V. (1983). The composing processes of advanced ESL students: six case studies. TESOL Quarterly, 17(2), 165-187.

Zamel, V. (1985). Responding to student writing. TESOL Quarterly, 19(1), 79 101.

\section{THE AUTHOR}

Alister Cumming is currently a doctoral candidate, as well as a research officer in the Educational Evaluation Centre, at the Ontario Institute for Studies in Education. He previously taught at Carleton University, Concordia University, and the University of British Columbia. 


\section{APPENDIX}

Percentage Gains (posttest-pretest scores) over Period of Study

Total Content Organization Vocabulary Language Use

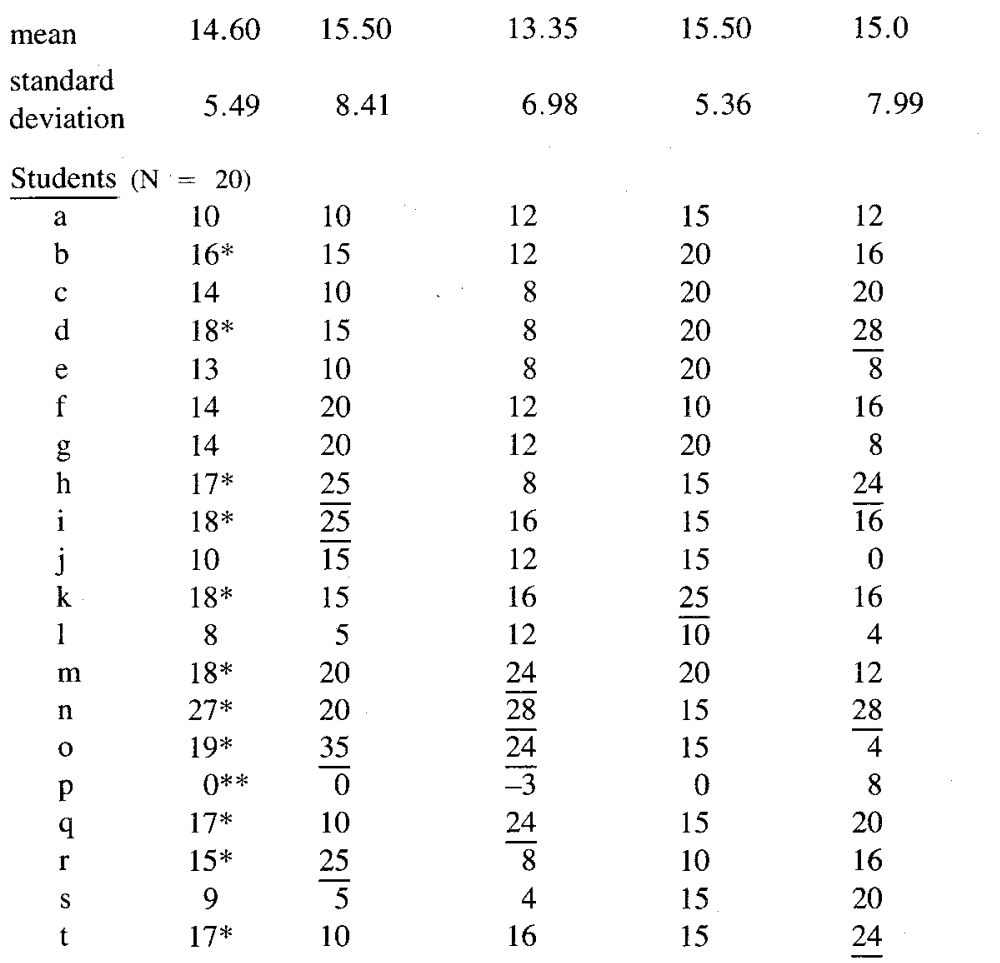

* = total gain greater than mean total gain

- $\quad$ = gain well above mean gain in sub-category (i.e. greater than standard deviation)

** $\quad=$ student committed major tactical error on posttest 